Journal of

Education and Practice

(JEP)

Impact of Positive Reinforcement on Pupils' Absenteeism: A Case Study at Felicomfort Junior High School (JHS), Amamoma in Cape Coast, Ghana
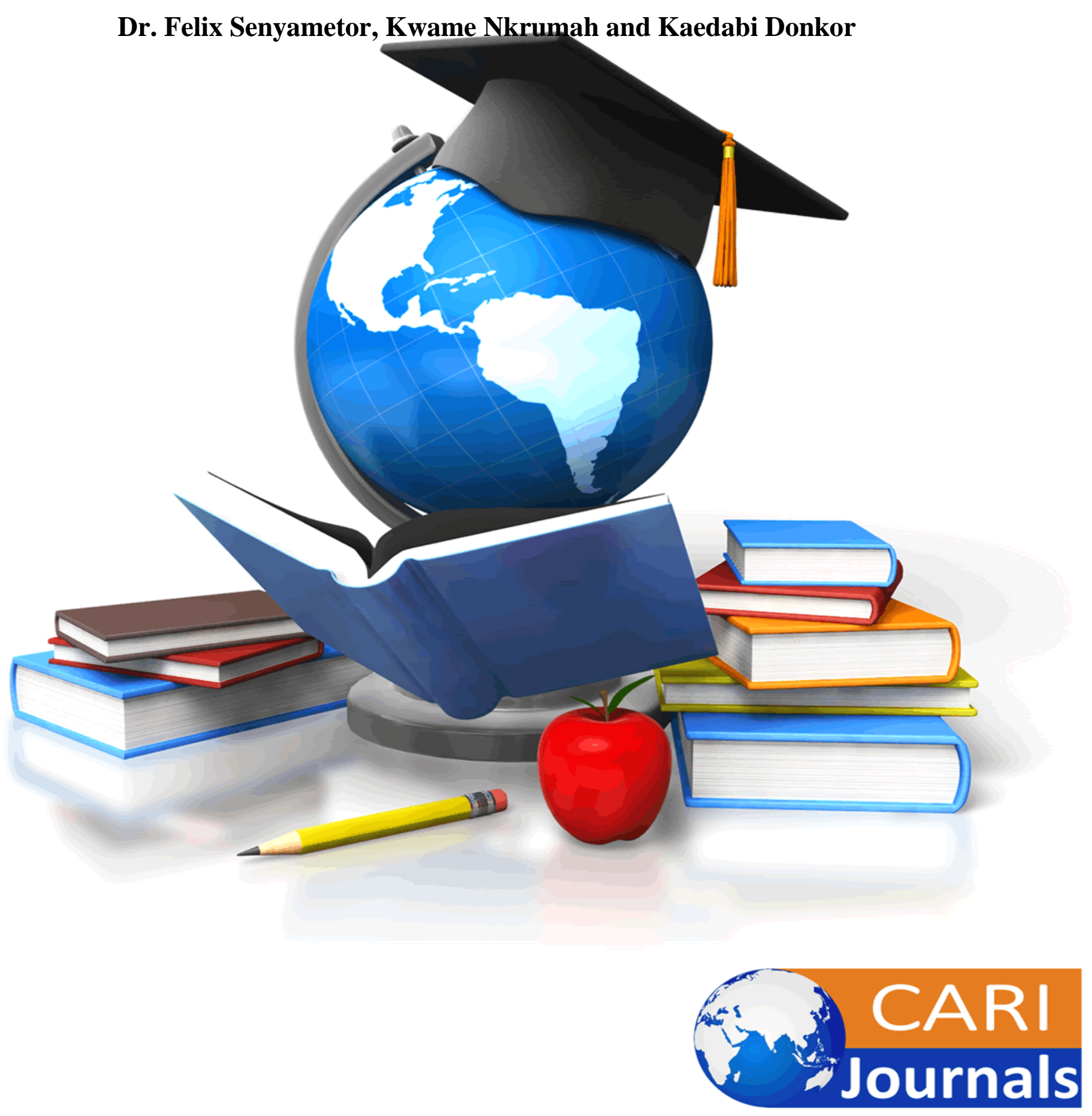
Journal of Education and Practice

ISSN 2520-467X (Online)

Vol.4, Issue No.2, pp 53 - 69, 2020

www.carijournals.org

\title{
Impact of Positive Reinforcement on Pupils' Absenteeism: A Case Study at Felicomfort Junior High School (JHS), Amamoma in Cape Coast, Ghana
}

${ }^{1 *}$ Dr. Felix Senyametor

Department of Education and Psychology, University of Cape Coast, Ghana

Corresponding Author's Email: felix.senyametor@ucc.edu.gh

${ }^{2}$ Kwame Nkrumah

College of Distance Education, University of Cape Coast, Ghana

Corresponding Author's Email: kwame.nkkrumah@ucc.edu.gh

${ }^{3}$ Kaedabi Donkor

College of Distance Education, University of Cape Coast, Ghana

Corresponding Author's Email: rebecca.kaedabi-donkor@ucc.edu.gh

\begin{abstract}
Purpose: This study focused on finding out the impact of positive reinforcement on pupils' absenteeism at Felicomfort JHS at Amamoma within the University of Cape Coast community.

Methodology: The quasi-experimental and descriptive designs were used in conducting the study. Both quantitative and qualitative approaches were employed in carrying out the study to get to the bottom of the phenomenon investigated. The population was 56 comprising Junior High School (JHS) One and Two pupils of the school. The sample size for the study was 14 pupils purposively sampled out of the total number of 56. Pre-intervention test, post-intervention test, interviews and questionnaires were used to collect data from respondents. Data analysis was done, using paired sample t-test, frequency and percentage counts with the Predictive Analytical Software (PASW) version 21 .
\end{abstract}

Findings: The study revealed a statistically significant difference in the pre-intervention results $($ Mean $=2.643$, Std. Dev. $=1.382)$ and that of the post intervention (Mean $=4.786$, Std. Dev. $=$ 1.829) $[\mathrm{t}=6.382, \mathrm{df}=13, \mathrm{p}=0.001]$. The eta square analysis was 89 percent $\left(\eta^{2}=0.89\right)$ indicating a significant impact of positive reinforcement on modifying pupils' behaviour of absenteeism. Analysis of the questionnaire revealed that $80 \%$ of the pupils became regular at school as a result of the application of positive reinforcement.

Unique contribution to theory, practice and policy: It was recommended that the government through the District Assemblies should offer financial assistance to poor parents and single parents to enable them adequately cater for their children at school.

Keywords: Reinforcement, motivation, absenteeism, basic school. 
Journal of Education and Practice

ISSN 2520-467X (Online)

Vol.4, Issue No.2, pp 53 - 69, 2020

www.carijournals.org

\subsection{INTRODUCTION}

According to Keter as (cited in Vidyakala \& Vaishnavi, 2015: 1) "absenteeism in school is the habit of staying away from school without providing a genuine or any reason for not attending classes" They added that absenteeism is a truant behaviour that negatively affects the academic achievement of pupils. Databank (2015), on the other hand, defined absenteeism as missing 10 percent or more of school days. Child Databank further found that habitual absence is an important early warning sign that a student is at risk for failure, early school dropout and a strong predictor of undesirable outcomes in adolescence, including substance abuse, gang involvement, and criminal activity.

Regular school attendance is a critical factor in school success among pupils. Research has shown that regular attendance is related to higher academic performance for school pupils of all backgrounds, particularly for pupils with lower socioeconomic status (Epstein \& Sheldon, 2002; Ready, 2010). Some research reports have shown that Family health or financial concerns, poor school climate, drug and alcohol use, transportation problems, and differing community attitudes toward education are among the factors often associated with pupils' consistent absence from school (Teasley, 2004).

According to Databank (2015) parental poverty, lack of reinforcement and rewards in the form of food for pupils were found to be among the leading causes of absenteeism. Databank (2015) findings further, revealed that schools where more than 50 percent of the pupils were offered free or reduced lunch price, recorded a little above 3 percent of absenteeism as compared to more than 10 percent rate of absenteeism in schools where there was no free feeding or reduced lunch price for primary school pupils. The rate of absenteeism was however different for older pupils in High Schools. In 2015, 23 percent of Basic 4 pupils who were offered free or reduced lunch price and other reinforcement packages were habitually absent, compared with a reduced rate (15\%) of absenteeism on the part of older pupils in Basic 8 who were not offered free or reduced lunch price and other reinforcement packages (Databank, 2015).

School pupils' rate of absenteeism appears to decrease as they travel high along the academic ladder. According to Databank (2015), from 1994 to 2005, there was no significant change in the percentage of Basic 8 pupils who were reported to be absent from school for three or more days (18\% in 1994 and $19 \%$ in 2015). However, among Basic 8 pupils this percentage declined slightly, from 22 percent in 1994 to 19 percent in 2015. If schools, districts and nations are to improve educational achievement, they need to address basic school absenteeism. To do so effectively, they need more and better data in order to know how many, and which group of pupils are chronically absent, and compare the number of days each pupil attends school with the number of days the pupil is supposed to attend school (Bruner, Discher \& Chang, 2011).

In Ghana, research has shown that parental factor (divorce, single parenting, parental unemployment, too busy schedules of parents and lack of parental reinforcement) constitutes 92 percent of the causes of school pupils' absenteeism (Nkansah, Ninson, Owusu \& Prempeh, 2017). Among school factors, corporal punishment and lack of teacher reinforcement (inability to counsel pupils, show love and care) represents 56 percent. Nkansah et al (2017) also reported 52 percent 
Journal of Education and Practice

ISSN 2520-467X (Online)

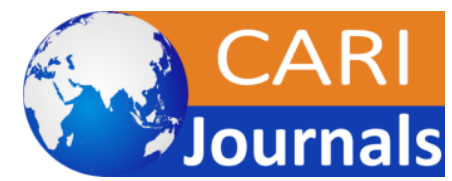

Vol.4, Issue No.2, pp 53 - 69, 2020

www.carijournals.org

poor academic achievement, 16 percent difficulty in making friends and 28 percent premature sexual activity as some effects of pupils' absenteeism.

Regular school attendance ensures continuity in the pupils' learning process but when they consistently absent themselves from class; it has an adverse effect on their academic performance and social life (Vidyakala \& Vaishnavi, 2015). In a similar vein, Lutheran (2017) found that pupils' regular school attendance aids them develop in terms of structure, academic achievement, language skills and social skills as follows:

i. Structure: Regular school attendance helps pupils to engage in the same activities and become more likely to develop structure. This structure instills a better sense of time management in them which will be useful in many facets of their lives.

ii. Achievement: Regular class attendance is more likely to help pupils pass reading and math assessments than students who do not. They are more likely to keep up with daily assignments and homework, and be better prepared for tests and quizzes.

iii. Language skills: Pupils are exposed to classes and activities that are crucial for developing language.

iv. Social skills. Regular school attendance help participate in many social situations that are vital for understanding the world around them. They socialize with peers who help them understand social cues, social etiquette, and how to express their thoughts.

Notwithstanding the positive gains in regular school attendance, our visit and review of pupils' attendance register at Felicomfort Junior High School (JHS) in Cape Coast revealed that 14 pupils were consistently absenting themselves from school. According to the headmaster and some tutors of the school, the situation was adversely affecting, smooth and progressive delivery of teaching as teachers sometimes had to repeat certain important lessons resulting in difficulty in completing some of the academic syllabi. According to the school, pupils were also suffering from negative academic and social development. It is against this background that we decided to use positive reinforcement as an interventionary measure to see whether this maladaptive behaviour could be corrected.

\subsection{Statement of the Problem}

Regularity of pupils at school ensures social, academic, intellectual, cultural and economic development of pupils. Loren (as cited in Senyametor, et al, 2018:3) found that school "absentees miss out on critical stages of social interaction and development with their peers academically". This, according to her, could lead to other adverse repercussions like low self-esteem, social isolation and dissatisfaction.

Despite the enormous benefits of regular school attendant, there are some factors that militate against it. Vidyakala and Vaishnavi (2015) for instance, found that factors such as family health or financial concerns, poor school environment, transportation problems, and differing community attitudes towards education affect pupils' absenteeism directly and indirectly.

According to Demir, Akman and Karabeyoglu (2015), there have been various studies geared toward establishing the causes of absenteeism in Turkey. These include reasons for basic school 
Journal of Education and Practice

ISSN 2520-467X (Online)

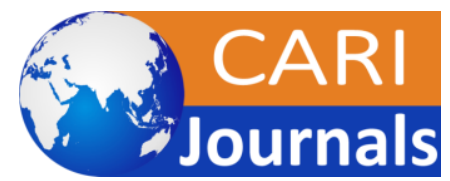

Vol.4, Issue No.2, pp 53 - 69, 2020

www.carijournals.org

absenteeism, reasons for secondary school absenteeism, and reasons for absenteeism in elementary and secondary level education.

Demir, Akman and Karabeyoglu (2015), outlined some statistics about the rates of absenteeism in a research conducted by the Education Reform Initiative (Egitim Reformu Girisimi - ERG) during the 2010-2011 academic year in Burdur, Turkey. The study revealed the following rates of pupils' absenteeism; $36 \%$ in public basic schools and $42 \%$ in the vocational-technical high schools which is above Turkey's national average of $28 \%$ for public schools. Rates for the high school students of Burdur seem to be quite high compared to the overall rate of the Turkish Mediterranean Region (25.4\% in public schools and $34.5 \%$ for technical schools). In the literature, as pointed out by Demir, Akman and Karabeyoglu (2015), the reasons for absenteeism are multifaceted. They include factors, such as student's perception of the school environment, student's commitment to school, student's family structure and student-family communication.

The canker of pupils' absenteeism appears to be a ubiquitous one. Felicomfort Junior High School in Cape Coast, Ghana is no exception. Out of the total population of 56 Junior High School (JHS) pupils in JHS One and Two, 14 of them were constant absentees (Felicomfort Junior High School JHS, 2017). There was an empirical research in the school to identify the factors responsible for it (Senyametor et al. 2018). The study investigated into three major factors of pupils' absenteeism (parental factor, pupil factor and teacher factor). Key findings of the study indicated that the overall percentage mean of pupils (58\%) discounted teacher factor as responsible for pupils' absenteeism, while 70 percent of the results indicated that parental lack of reinforcement was the major cause of pupils' absenteeism. The question is; how could this maladjusted behaviour of pupils at the Felicomfort JHS be modified through the application of positive reinforcement? This is the gap in research that study came to fill.

\subsection{Objectives of the Study}

The objective of this study was to examine the impact of positive reinforcement on pupils' absenteeism at Felicomfort JHS at Amamoma within the University of Cape Coast community. Specifically, the study sought to examine the:

1. Rate of absenteeism of pupils at the Felicomfort Junior High School (JHS)

2. Effect of the application of reinforcement as an interventionary measure of pupils' absenteeism at Felicomfort Junior High School?

\subsection{Research Questions}

3. What is the rate of absenteeism of pupils at the Felicomfort Junior High School (JHS)?

4. What is the effect of the application of reinforcement as an interventionary measure of pupils' absenteeism at Felicomfort Junior High School? 
Journal of Education and Practice

ISSN 2520-467X (Online)

Vol.4, Issue No.2, pp 53 - 69, 2020

www.carijournals.org

\subsection{Research Hypothesis}

${ }^{1}$ Ho: There is no statistically significant difference between the pre-intervention and postintervention results regarding the effect of positive reinforcement on pupils' absenteeism at Felicomfort JHS.

\subsection{LITERATURE REVIEW}

\subsection{The Theory of Reinforcement}

The reinforcement theory propounded by Skinner (1963) refers to the process of modifying behaviour by reinforcing it consistently through giving positive or negative reinforcement. The goal being to increase the probability that the rewarded (reinforced) behaviour will occur more frequently, those behaviours not rewarded will die out (extinct), and those met with unpleasant (punishment) consequences will be weakened (Myers, 2007). In the classroom, reinforcement occurs as teachers manage the environmental events that follow students' desired ways of behaving so to increase the strength and future likelihood of that behaviour (Aggarwal, 1995).

Reinforcement comes in two types, positive and negative. Positive reinforcement occurs when desired behaviour is strengthened by the presentation of a contingent stimulus. The attractive, behaviour-increasing, contingent stimulus used during positive reinforcement is referred to as a positive reinforcer. A positive reinforcer is defined as any environmental event that when given in response to the behaviour, increases the strength and frequency of that behaviour. Some commonly used positive reinforcers in the classroom are praise, attention, tokens, and stickers (Johnmarshall, 2009).

Negative reinforcement occurs when desired behaviour is strengthened by the removal of a contingent stimulus (Johnmarshall, 2009). The aversive, behaviour increasing, contingent stimulus that is removed during negative reinforcement is referred to as a negative reinforcer. A negative reinforcer is defined as any environmental event that, when taken away in response to the behaviour, increases the strength and frequency of that behaviour. Some commonly used negative reinforcers in the classroom are taking away an aversive assignment (homework), withdrawing an intrusive stare, or canceling a chore. What is common to all positive reinforcers is the idea that after the student engages in a particular behaviour, he or she receives an attractive consequence for doing so (Johnmarshall, 2009). What is common to all negative reinforcers is the idea that when the student engages in a particular behaviour, he or she gets an unattractive or aversive stimulus for doing so.

In order to understand the concept of motivation and reinforcement, Porter and Lawler (as cited in Aggarwal, 1995) used Victor Vroom's expectancy theory as a foundation to develop their expectancy model. Similar to Vroom's theory, Porter and Lawler concluded that an individual's motivation to complete a task is affected by the reward and reinforcement they expect to receive for completing the task (Amponsah, Senyametor \& Gyambrah, 2015). In the light of modifying the maladjusted behaviour (absenteeism) identified at Felicomfort JHS, the continuous and partial reinforcement schedules were used. 
Journal of Education and Practice

ISSN 2520-467X (Online)

Vol.4, Issue No.2, pp 53 - 69, 2020

www.carijournals.org

Every basic school pupil expects something of value as a result of his/her effort of coming to school, in the form of good teaching, warm interest and attention from teachers, awards and recognition among others. Therefore, pupils' motivationt to put much effort in every day school attendance is predicated on the value of what parents and teachers reinforce them with. The reinforcement could be in the form of counselling on the importance of education, show of interest and attention, provision of school uniforms and learning materials as well as money for food at school (Senyametor, Gyimah \& Vincent, 2018).

According to Porter and Lawler (as cited in Amponsah, Senyametor \& Gyambrah, 2015), human engagement in an activity or performance is mediated by abilities, traits and role perception. This implies that regularity of pupils at school depends on giving maximum attention to education of pupils on the relevance of education, and counselling on how to overcome their negative attitudes or acts that rob them of regular school attendance. This would undoubtedly help them perceive the act of going to school every day as within their capabilities.

\subsection{How Teachers and Parental use of Positive Reinforcement affect Pupils' Rate of Absenteeism}

Reinforcement is defined by its effect on behaviour. Only environmental events that actually increase behaviour are reinforcers. If events such as a smile, biscuit, or break from chores do not increase the student's behaviour in performing desired activities, then the event is not actually a reinforcer. This qualification of which environmental events are rein-forcers and which are not is an important point because teachers often implement consequences haphazardly (noncontingently) or inconsistently (Kauffman, 1996; Pullen, 2004). This means that if regular school attendance of pupils should be reinforced with praises, pens, mathematical sets, school bags and exercise books, it should only be on condition of initial registration of the desired behaviour. Praise represents a good example of commonly used attractive environmental event that is used for a dozen different reasons, only one of which is to reinforce (increase) students' behaviour (Brophy, 1981).

Furthermore, according Wehby, Symons, Canale, and Go (as cited in Johnmarshall, 2009), teachers neither show interest, attention nor reinforce positive behaviours as often as they could. Instead of delivering contingent rewards for desired behaviour (i.e., reinforcers), what teachers more typically offer to students are promises of reward. A reward is the offering of an environmental event in exchange for the student's participation, service, or achievement (Craighead, Kazdin, \& Mahoney, 1981). Many positive educational outcomes can be framed in terms of desirable behaviour. Teachers, administrators, and parents should consider behaviours such as attending school regularly and promptly, being actively engaged during classroom lessons, and showing respect for others, making good grades, and graduating from school as desirable ways to behave. Therefore, according to Kauffman (1996), if parents and teachers extrinsically and intrinsically reinforce these behaviours, it will turn to increase their frequency.

However, Deci and Ryan (as cited in Johnmarshall, 2009), put forward a dissenting view on the foregoing assertion on the desired effects of extrinsic motivation on behaviour by saying that those extrinsic rewards often hinder students' intrinsic motivation and capacity for autonomous selfregulation. In fact, this argument is in tandem with that of Koomson, Brown, Ahiatrogah and Dowson-Brew (2012), who opined that offering tangible gifts as reinforcement devalues pupils' 
Journal of Education and Practice

ISSN 2520-467X (Online)

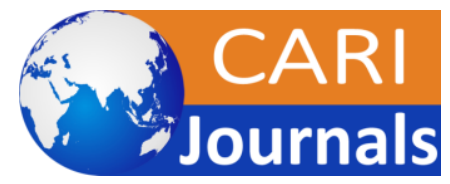

Vol.4, Issue No.2, pp 53 - 69, 2020

www.carijournals.org

behaviour by acting as "bribes". According to them, when extrinsic rewards are withdrawn, desired behaviour would extinct and would cease to strengthen the desired behaviour. In the midst of all this controversy, we believe that extrinsic rewards as opined by Maslow, Skinner and Thorndike as cited in Myers (2007) positively affect behaviour. Their deleterious ramifications on behaviour would emanate from their inappropriate application. That is not applying or following them immediately after the desired behaviour, or applying them haphazardly such that they are not contingent on registration of desired or expected behaviour. Therefore, if extrinsic rewards are applied contingent on desired or expected behaviour, negative behaviours like pupils habitual absenteeism could be modified.

\subsection{Reinforcement and Absenteeism}

A study conducted by Johnmarshall (2009) on how reinforcers and rewards are related to learning. He examined how positive and negative reinforcement influence kindergarten pupils to pay attention and be regular at school. He presented these issues in Table 1.

Table 1: Examples of Positive and Negative Reinforcers Commonly used in Basic Schools

\begin{tabular}{ll}
\hline Positive reinforcers & Negative reinforcers \\
\hline Giving praise & Taking away a deadline \\
Giving stickers & Taking away unattractive assignment \\
Giving tokens & Taking away a threat \\
Giving attention & Removing bad grades \\
Giving good grades & Removing bad grades \\
Giving scholarships & Taking away criticism \\
Giving an honour & Stopping one's ridicule \\
Giving a prize & Stopping one's yelling or screaming \\
Giving an award & Stopping one's crying \\
Giving food & Stopping one's whining \\
Giving money & Stopping one's staring \\
Giving smile & Stopping one's pleading or pouting \\
Giving positive feedback & Stopping laughing (at someone) \\
\hline
\end{tabular}

Table 1 provides a sample of reinforcers commonly used in basic school classrooms. The left side of the Table lists a variety of positive reinforcers that teachers give to strengthen students' behaviour, while the right side of the Table lists a variety of negative reinforcers that teachers take away to strengthen students' behaviour. The study revealed $85 \%$ of pupils paying attention in class as well as becoming regular at school, as a result of the application of reinforcement. The study also established a statistically significant difference between his pre-intervention and post intervention scores as a result of positive reinforcement. He therefore, concluded that consistent and appropriate application of positive and negative reinforcement as in the provision of things outlined in Table 1 is a powerful tool in behaviour modification. 
Journal of Education and Practice

ISSN 2520-467X (Online)

Vol.4, Issue No.2, pp 53 - 69, 2020

www.carijournals.org

\subsection{METHODOLOGY}

\subsection{Research Design}

The quasi-experimental and descriptive designs were used for the study. Quasi-experimental design is used when the researcher is concerned with independent variables that cannot be assigned randomly. This happens when the intact group is used as done in this study (Cohen, Manion \& Morriso, 2007). Both quantitative and qualitative approaches were employed in the conduct of the study to arrive at valid conclusions of the phenomenon investigated.

\subsection{Population and Sample}

The population comprised 10 teachers, 10 parents and all Junior High School pupils (JHS) of Felicomfort Junior High School JHS at Amamoma in the first and second years totaling 110, made up of 79 males and 31 females (Felicomfort Junior High School JHS, 2016). The sample for this study was 14 pupils ( 9 males and 5 females) purposively selected from their total population of 56 in the first and second years of Felicomfort JHS at Amamoma in Cape Coast. The JHS 3 pupils were not included in the study because they were writing their Basic Education Certificate Examination (BECE) at the time this study was taking place. The pupils were purposefully sampled because; they were the people battling with the problem of absenteeism and were knowledgeable about the phenomenon under study. Ten (10) teachers and 10 parents were also purposively sampled for the study

\subsection{Data collection Instrument}

Examination of pupils' attendance register, questionnaires, unstructured interview and structured interview were used to collect data for the study. Examination of the attendance register was done to identify those pupils who were consistently absenting themselves from school.

\subsection{Data Collection Procedure}

Primary and secondary data were used. The primary data were collected through questionnaires and unstructured interview. The pretest and posttest could not capture the opinions of respondents on how the intervention actually impacted on them. Therefore, in the form of triangulation, respondents were interviewed and questionnaires administered to them to respond to in order to seek their views on how the intervention actually impacted on their absenteeism. Secondary data on the other hand, were collected through review of existing document like class registers. At the end of data collection, 9 male pupils and 5 female pupils were captured.

\subsection{Procedure for Data analysis}

Data analysis and comparison of the pre-intervention and post intervention tables were done to assess the impact of the positive reinforcement as an interventionary measure. Both descriptive and inferential statistics were used to analyse the research question and test the hypothesis. Data collected from the field were edited, coded and entered into the Statistical Product for Service Solutions (SPSS) version 20 programme on the computer and analyzed into Tables and percentages for interpretation. The research questions were analyzed using frequency and percentage counts. The paired sample t-test was also used to analyse the hypothesis. The unstructured interview data were analysed using interpretation of patterns and themes. 
Journal of Education and Practice

ISSN 2520-467X (Online)

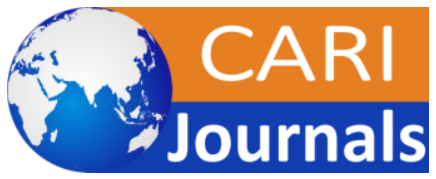

Vol.4, Issue No.2, pp 53 - 69, 2020

www.carijournals.org

\subsection{RESULTS AND DISCUSSION}

\subsection{Research Question One: What is the rate of absenteeism of pupils at the Felicomfort Junior High School? \\ 4.2 Pre-intervention}

In line with the objectives of the study, data was collected through examination of pupils' rate of absenteeism from their attendance register for two weeks and the corresponding percentages. Table 3 shows the results of pupils' attendance and their percentages for two weeks.

Table 2: Results of pupils' Rate of Absenteeism at Felicomfort Junior High School JHS 1 \& 2 for two weeks

\begin{tabular}{lll}
\hline Pupil & Attendance & Percentage (\%) \\
\hline 1 & $2 / 10$ & 20 \\
2 & $4 / 10$ & 40 \\
3 & $1 / 10$ & 10 \\
4 & $3 / 10$ & 30 \\
5 & $4 / 10$ & 40 \\
6 & $5 / 10$ & 50 \\
7 & $3 / 10$ & 30 \\
8 & $2 / 10$ & 20 \\
9 & $2 / 10$ & 20 \\
10 & $1 / 10$ & 10 \\
11 & $2 / 10$ & 20 \\
12 & $4 / 10$ & 40 \\
13 & $1 / 10$ & 10 \\
14 & $3 / 10$ & 30 \\
\hline Mean total & $\mathbf{3 / 1 0}$ & $\mathbf{3 0 / 1 0 0}$ \\
\hline
\end{tabular}

As depicted in Table 2, attendance of pupils was examined for two consecutive weeks and the total average attendance was 3 out of 10 days representing 30 percent. Only one pupil was able to continuously attend school for 5 days out of the 10 days (50\%). This shows a very high rate of pupls' absenteeism at the Felicomfort JHS. This finding is not quite different from the findings of the Education Reform Initiative (Egitim Reformu Girisimi - ERG) during the 2010-2011 academic year (as cited in Demir, Akman and Karabeyoglu, 2015) in Burdur, Turkey which reveals the following rates of pupils' absenteeism; 36 percent in public basic schools and 42 percent in the vocational-technical high schools. Rates for absenteeism in Burdur Turkey appear to be quite higher than that of Felicomfort Junior High School (JHS) in Cape Coast, Ghana. Research has shown that parental factor (divorce, single parenting, parental unemployment, too busy schedules of parents and lack of parental reinforcement) constitutes 92 percent of the causes of school pupils' absenteeism (Nkansah, Ninson, Owusu \& Prempeh, 2017). Among school factors, corporal punishment and lack of teacher reinforcement (inability to counsel pupils, show love and care) represents 56 percent of the causes of problem (Nkansah et al, 2017) also reported 52 percent under academic achievement, 16 percent difficulty in making friends and 28 percent premature sexual activity as some effects of pupils' absenteeism. 
Journal of Education and Practice

ISSN 2520-467X (Online)

Vol.4, Issue No.2, pp 53 - 69, 2020

www.carijournals.org

\subsection{Analysis of Unstructured Interviews}

Ten (10) class teachers and 14 pupils of the Felicomfort Junior High School Junior High School (JHS) as well as Parents of absentee pupils were interviewed. Some teachers accused some pupils of consistently absenting themselves from school without any justifiable cause. Five class teachers for instance said "we often find some of these absentees hiding in town, playing cards with friends and engaging in gambling activities after informing their parents that they were going to school". Some pupils too accused their teachers of being too harsh, impatient and not caring to find out from them why they were absenting themselves from school. A pupil for instance said: "My class teacher only punishes me for absenting myself from school without finding out from me reasons for my absenteeism". Another pupil also said "I lost interest in attending school because, my class teacher gets annoyed whenever I ask questions about some concepts I don't understand, accusing me of not understanding because of my absenteeism". A 20 year, pupil, the oldest among the respondents said "some of my friends and I decided to go for gambling instead of going to school because, it is the fastest way of making money. Education doesn't fetch us quick income". Some pupils, on the other hand, blamed their absenteeism on some of their parents for not providing them with "chop" money, school uniform, exercise books, and money to pay for extra class and the like. A pupil from a single parent for instance said: "Everyday my mother says she doesn't have money to pay for my transport to school and food at the school canteen." Two male pupils from same parents also said: "Our parents don't care about whether we attend school or not, so we attend school as and when we feel like attending". Some parents admitted that due to poverty, loss of spouse and broken homes, they were not able to gather enough funds and resources to adequately care for their wards at school. A parent for instance said "I know am poor but always try to meet my ward half way". A few of the parents interviewed however denied ever shirking their responsibilities to care for their wards at school and blamed their wards' absenteeism on bad associations of their wards. A parent said "I bought exercise books, paid school fees and everything that my two children needed for school. I don't see why they refused to attend school". Through interviews some of the pupils and some parents revealed that part of the problem was attributable to their lack of knowledge about the importance of education. Careful analysis of parents, pupils and teachers' responses revealed that pupils' absenteeism was due to lack of seriousness and commitment on the part of pupils themselves. Most of the pupils' therefore, were not wholly truthful about blaming their absenteeism on parents and teachers. This finding contradicts the earlier one in the same school (Felicomfort JHS) by Senyametor, Gyimah, Minadzi, (2018) which revealed 70 and 58 percent of pupil' absenteeism was caused respectfully by parents and teachers. The researchers therefore, planned for an intervention targeted at reforming the pupils.

\subsection{Intervention}

Based on the principles of the theory of reinforcement, schedules of continuous and partial reinforcement were applied for 5 months as follows:

Although the concept of behaviour modification may seem theoretically complicated, its real life application is actually quite simple. If a person is reinforced every single time he or she does something good, eventually the reinforcement loses its power (Myers, 2007). Therefore when we were applying the reinforcement theory to modify the maladaptive behaviour of the pupils who were consistently absenting themselves from school, we initially reinforced desired behaviour of 
Journal of Education and Practice

ISSN 2520-467X (Online)

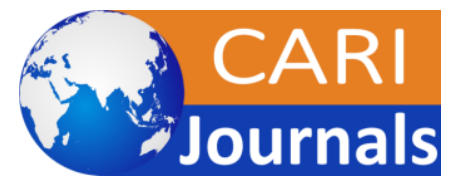

Vol.4, Issue No.2, pp 53 - 69, 2020

www.carijournals.org

regular school attendance consistently with warm embrace, praises, pens, exercise books, school bags and mathematical sets, and then as they started to respond by being a little regular at school, we changed the schedule of reinforcement to every one week they consistently attended school. After a while, we changed it again to every two weeks of regular school attendance. We were cautious by not explicitly connecting our rewards and commendations or praises to their regular school attendance, but made sure that our rewards, praises or commendations directly followed the desired behaviour (regularity to school). It took some time but eventually 12 out of the 14 pupils started becoming regular to school on a fairly consistent basis after three weeks. Once that happened we did not give rewards, commend actions or praise every time. Instead, we changed from a modification stage to a maintenance stage and reward and or commended them on average every fourth to fifth week time they became regular to school.

The researchers went ahead to educate them on the importance and prospects of education and finally, conducted them round the University of Cape community to see doctors, nurses, bankers and lecturers who have made it in life through regular school attendance when they were in their formative years like them. The intervention spanned 5 months.

\subsection{Effect of the application of positive reinforcement (intervention) on pupils' absenteeism at Felicomfort Junior High School JHS?}

Issues examined included whether or not researchers' educating them on the importance of education, provision of pens, pencils, mathematical sets, school bags and show of interest in pupils reinforced them to be regular at school. Other issues looked at included whether or not our taking of pupils around the UCC campus to see how bankers, lecturers, administrators and nurses got to where they are due to regular school attendance when they were pupils like them and if parents and teachers frequently show similar interest, attention and care for them will reinforce them to be regular at school. In all five items were analysed and the results are presented in Table 3: 
Journal of Education and Practice

ISSN 2520-467X (Online)

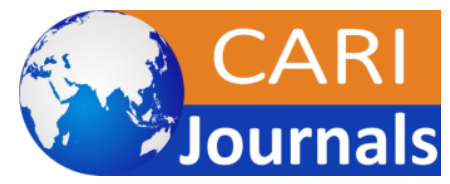

Vol.4, Issue No.2, pp 53 - 69, 2020

www.carijournals.org

Table 3: The effect of the Application of Reinforcement on Absenteeism

\begin{tabular}{lccc}
\hline $\begin{array}{l}\text { Effects of the application of } \\
\text { reinforcement on habitual absenteeism }\end{array}$ & No & $\begin{array}{c}\text { Agree } \\
(\%)\end{array}$ & $\begin{array}{c}\text { Disagree } \\
\text { No }(\%)\end{array}$ \\
\hline
\end{tabular}

I have decided to attend school regularly because the visitors to the

school showed interest in me.

$\begin{array}{lll}12 & 85.7 & 2\end{array}$

14.3

I have decided to regularly attend school because the visitors to the school educated me on the importance of education.

$\begin{array}{llll}12 & 85.7 & 2 & 14.3\end{array}$

I have decided to regularly attend school because the visitors to the school at times reward my little effort of attending school with pencils, pens and other necessities.

$\begin{array}{llll}10 & 71.4 \quad 4 & 28.5\end{array}$

I have decided to regularly attend school because the visitors to the school conducted me around the UCC campus to see how bankers, lecturers, administrators and nurses got to where they are due to regular school attendance when they were pupils like me.

My parents and teachers frequently show similar interest, attention and care for me, I will always be regular at school.

\begin{tabular}{llll}
13 & 92.8 & 1 & 7.1 \\
\hline & $\mathbf{8 0}$ & $\mathbf{2 0}$
\end{tabular}

Percentage mean

As depicted in Table 3, majority (85.7\%) of the respondents agreed that our show of interest in them and educating them on the importance of education actually reinforced them to be regular at school. On the other hand, 71.4 percent of respondents agreed that rewarding their little effort of attending school for some few days actually reinforced them to modify their behaviour and decided to be regular at school subsequently. Similarly, majority (92.8\%) agreed that if parents and teachers frequently showed keen interest, attention and care for them, they would always be regular at school.

The findings corroborated that of our post-intervention results, which revealed that 12 pupils out of 14 recorded between 80 to 100 percent of regular school attendance as a result of the application of reinforcement, while only 2 of them recorded below 70 percent as a result of the intervention. It could be seen clearly that overall, pupils' attendance improved significantly.

These findings are in tandem with Skinners' theory of reinforcement as cited in Myers (2007) which refers to the process of reinforcing behaviour by consistently giving positive or negative reinforcement. The goal being to increase the probability that the reinforced behaviour will reoccur more frequently whereas those behaviours not rewarded will die out (extinct), and those met with unpleasant (punishment) consequences will be weakened. Because pupils' act of attending school was met with pleasant consequences or rewards, they decided to eschew absenteeism. These findings are also in congruence with Vroom's expectancy theory as cited in Aggarwal (1995) which says that the amount of energy exerted is dependent upon the interaction of the input variables of value of reward. This means, school pupils' regularity at school is reinforced by the value of all the necessary things that they are provided with. 
Journal of Education and Practice

ISSN 2520-467X (Online)

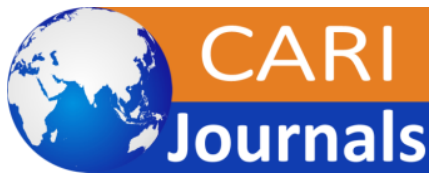

Vol.4, Issue No.2, pp 53 - 69, 2020

www.carijournals.org

\subsection{Post Intervention}

4.7 Research Question Two: What is the effect of the application of reinforcement (intervention) on pupils' absenteeism at Felicomfort Junior High School JHS?

After the intervention, pupils' attendance register was re-examined in order to access the impact of the intervention on their school attendance. The results are presented in Table 4:

Table 4: The effect of the application of reinforcement (intervention) on pupils' absenteeism at Felicomfort Junior High School JHS

\begin{tabular}{lcc}
\hline Pupils & Attendance for 10 days & \% of sch. Attendance \\
\hline 1 & $10 / 10$ & 100 \\
2 & $8 / 10$ & 80 \\
3 & $10 / 10$ & 100 \\
4 & $10 / 10$ & 100 \\
5 & $5 / 10$ & 50 \\
6 & $10 / 10$ & 100 \\
7 & $8 / 10$ & 80 \\
8 & $6 / 10$ & 60 \\
9 & $10 / 10$ & 100 \\
10 & $9 / 10$ & 90 \\
11 & $10 / 10$ & 100 \\
12 & 910 & 90 \\
13 & $8 / 10$ & 80 \\
14 & $10 / 10$ & 100 \\
\hline Mean & & $\mathbf{8 8}$ \\
\hline
\end{tabular}

Table 4, shows 7 pupils recording 100 percent of regular school attendance as a result of the application of positive reinforcement. Five of the pupils too recorded between 80 to 90 percent of regular school attendance while 2 of them recorded below 70 percent as a result of the intervention. It could be seen clearly that overall pupils' attendance improved significantly $(88 \%)$ after the interventionary measures. These findings are in line with Skinner's (1963) theory of reinforcement which states that when responses (behaviour) of people are met with favourable consequences, such responses or behaviour are likely to be repeated in future. Therefore, if parents and teachers reinforce absentees' act of school attendance by providing them with food, money, school bags, learning materials and frequently educate their them about the importance of education, school absenteeism would be curtailed.

The findings however, contradicts that of Databank (2015) who found that 23 percent of Basic 4 pupils who were offered free or reduced-price lunch and other reinforcement packages were habitually absent, compared with a reduced rate (15 percent) of older pupils in Basic 8 who were not offered free food and reinforcement package. This contradiction could be attributed to differences in respondents and study settings of both studies, or to the fact that those things offered in the Databank (2015) report were not things of value to the pupils as posited by an aspect of Vroom's (1964) expectance theory (valence) which refers to the value people place on the outcome 
Journal of Education and Practice

ISSN 2520-467X (Online)

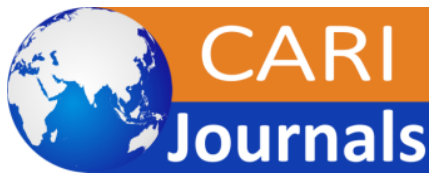

Vol.4, Issue No.2, pp 53 - 69, 2020

www.carijournals.org

or reward. Generally, the higher the value (importance) of the outcome or reward, to the recipient, the better the chance of it reinforcing the desired behaviour (Lussier \& Achua, 2011).

\subsection{Hypothesis Testing}

4.9 Research Hypothesis One: There is no statistically significant difference between the pre-intervention and post intervention results regarding the effect of positive reinforcement on pupils' absenteeism at Felicomfort JHS.

After the pre-intervention and post intervention results of the study, we went further to find out whether there was any significant difference between the results regarding the effect of positive reinforcement on pupils' absenteeism at the Felicomfort JHS, using paired sample t-test. The results are presented in Table 5.

Table 5: Difference between pre-intervention and post-intervention results regarding the effect of reinforcement on pupil' absenteeism at Felicomfort JHS

\begin{tabular}{lcccccc}
\hline Variables & $\mathbf{N}$ & Mean & Std. Dev. & t-value & p-value & $\boldsymbol{\eta}^{\mathbf{2}}$ \\
\hline Pre-intervention & 14 & 2.643 & 1.382 & $6.382^{* *}$ & 0.001 & \\
Post intervention & 14 & 4.786 & 1.829 & & & 0.89 \\
\hline
\end{tabular}

$* * p<0.01, * p<0.05 d f=13(N=14)$

Table 5 results show that there was a statistically significant difference between pre-intervention results $($ Mean $=2.643$, Std. Dev. $=1.382)$ and post intervention $($ Mean $=4.786$, Std. Dev. $=1.829)$ results $[\mathrm{t}=6.382, \mathrm{df}=13, \mathrm{p}=0.001]$ This result clearly shows that there is a significant mean difference between pre-intervention and post-intervention results regarding the effect of reinforcement on pupil' absenteeism at Felicomfort JHS. Based on Cohen (as cited in Pallant, 2014), guidelines on the interpretation of the eta square, the magnitude of the difference between the mean scores of the pre-intervention and post intervention results was large [eta square $\left(\eta^{2}\right)=$ 0.89). This shows that 89 percent of the variances regarding the regularity of pupils at school after the intervention could be explained by the effect of the application of positive reinforcement on pupils. Based on this finding, the study rejects the hypothesis for the study which states that, there is no statistically significant difference between pre-intervention and post intervention results. This is because the result clearly shows that, there is in fact, a statistically significant difference between pre-intervention and post-intervention results regarding the effect of reinforcement on pupil' absenteeism at Felicomfort JHS. This implies that positive reinforcement is an effective tool for modifying Felicomfort JHS pupils' behaviour of absenteeism. This finding is in line with Johnmarshall (2009) whose study established significant difference between pre-intervention and post intervention results and further recorded $85 \%$ of the effect of reinforcement on pupils' absenteeism. 
Journal of Education and Practice

ISSN 2520-467X (Online)

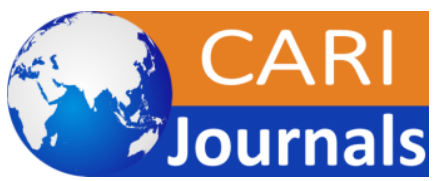

Vol.4, Issue No.2, pp 53 - 69, 2020

www.carijournals.org

\subsection{SUMMAY OF KEY FINDINGS, CONCLUSIONS AND RECOMMENDATIONS}

\subsection{Summary of Key Findings}

Based on the study, the following key findings are presented:

1. Total average attendance was 3 out of 10 days representing 30 percent. Only one pupil was able to continuously attend school for 5 days out of the 10 days (50\%). This shows a very high rate of pupls' absenteeism at the Felicomfort JHS.

2. Twelve (12) pupils out of 14 recorded between 80 to 100 percent of regular school attendance as a result of the application of positive reinforcement while only 2 of pupils recorded below 70 percent. It could be seen clearly that the overall pupils' attendance improved significantly after the interventionary measure.

3. Majority ( $80 \%)$ of the pupils agreed that the modification of their behaviour of absenteeism for the better by regularly attending school was due to the application of positive reinforcement on them.

\subsection{Conclusions}

Most school pupils expect parents and teachers to show interest in them and provide all their physical, emotional and educational needs as way of reinforcing them to attend school regularly. Habitual absenteeism has been a herculean problem for many schools. It adversely affects teaching, as teachers would always have to repeat some critical lessons for the sake of absentees hence affecting the smooth flow of lessons.

A convenient characteristic of pupils is that, they find reinforcement in the performance of many activities. Thus, it is often not necessary to provide external reinforcers. External reinforcement may be important to get pupils behaviour started, like ensuring regularity of school attendance but more natural reinforcers should be employed to take over after pupils gain basic competence and concepts in new behaviour being learnt. Based on the findings of this study, we could conclude that the application of the reinforcement theory as propounded by Skinner (1963) is a potent behaviour modification tool that school teachers and administrators could use when faced by similar behavioural problems posed by school pupils.

\subsection{Recommendations}

Based on the key findings and conclusions of this study, the following recommendations are made for consideration.

1. The government, through the metropolitan, municipal and district assemblies, should offer scholarships to brilliant but needy pupils who come from poor and low socioeconomic backgrounds as a way of reinforcing them to eschew absenteeism due to lack of basic education materials.

2. Parents should try as much as possible to provide all the basic needs of their wards including education materials.

3. Teachers of basic schools should always show interest in their pupils, especially those who usually absent themselves from school and find out from them the causes of their absenteeism. 
Journal of Education and Practice

ISSN 2520-467X (Online)

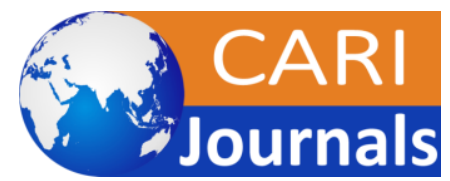

Vol.4, Issue No.2, pp 53 - 69, 2020

www.carijournals.org

4. School authorities should always hold Parent Teacher Association (PTA) meetings and discuss ways of resolving the issue of absenteeism and other problems of school pupils.

\section{REFERENCES}

Aggarwal, J. C. (1995). Essentials of educational psychology. Vikas Publishing House PVT Ltd. Amedahe, F. K. (2002). Fundamentals of educational research methods. UCC Press

Amponsah, M. O., Senyametor, F. \& Gyambrah, M. (2016). An assessment of basic school teachers' perception of motivation on their productivity Ghana. Published article, University of Cape Coast.

Brophy, J. (1981). Teacher praise: A functional analysis. Review of Educational Research, V (51), 5-32.

Bruner, C., Discher, A., \& Chang, H. (2011). Chronic elementary absenteeism: A problem hidden in plain sight. A Research Brieffrom Attendance Works and Child and Family Policy Center. http://www.edweek.org/media/chronicabsence-15chang.pdf

Cohen, L., Manion, L., \& Morrison, K. (2007). Research methods in education. Routledge.

Craighead, W. E., Kazdin, A. E., \& Mahoney, M. J. (1981). Behaviour modification: Principles, issues, and applications. Boston: Houghton Mifflin.

Databank. C. T. (2015). Student Absenteeism. https://www.childtrends.org/?indicators=studentabsenteeism.

Demir, K. \& Akman Karabeyoglu, Y. (2015). Factors Associated with Absenteeism in High Schools. www.ejer.com.tr/index.php?git=22\&kategori $=159 \&$ makale $=1008$

Epstein, J. L. \& Sheldon, S. B. (2002). Present and accounted for: Improving student attendance through family and community involvement. Journal of Educational Research, 95(5), 308318

Felicomfort, JHS. (2016). Felicomfort JHS attendance records. Amamoma: Cape Coast Felicomfort JHS

Johnmarshal, M. (2009). Chronic school absenteeism and the role of adverse childhood experiences. https://www.ncbi.nlm.nih.gov/pubmed/28927940

Kauffman, J. M. (1996). Research to practice issues. Behavioral Disorders, 22, 55-60.

Koomson, A. K., Brown, P., Anyagre, P., Ahiatrogah, P., \& Dawson-Brew, F. (2017). Educational psychology. Cape Coast: College of Distance Education, University of Cape Coast.

Lussier, R. N., \&Achua, F. C. (2011). Leadership; theory, application, skill development. New York: South Western Publishing.

Lutheran, P. (2017). Church Human Resource Policy Manual. https://www.rmselca.org/.../st_philip_lutheran_church_human_resource_policy_manu.

Myers, D. G. (2007). Exploring psychology (7th ed.). Worth publishers.

Nkansah, N., Ninson,S., Owusu, B. F. \& Prempeh, O. L. ( 2017). The impact of absenteeism on the academic performance of pupils of Ebom-Bomfa JHS. Unpublished dissertation. University of Cape Coast.

Pallant, J. (2014). SPSS survival manual: A step by step guide to data analysis using SPSS for Windows (Version 19). Lisbourne: Allen and Unwin. 
Journal of Education and Practice

ISSN 2520-467X (Online)

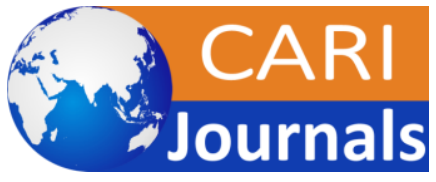

Vol.4, Issue No.2, pp 53 - 69, 2020

www.carijournals.org

Pullen, P. C. (2004). Phonological awareness assessment and instruction: A sound beginning. https://www.researchgate.net/publication/261063471_Lane_H_B_Pullen_P_C_2004_Ph nologicl_aw

Sarantakos, S. (1998). Social research. London: Macmillan.

Senyametor, F., Gyimah, E., \& Minadzi, V. M. (2018). Factors causing pupils' absenteeism at felicomfort junior high school at Amamoma in Cape Coast. Ghana: Cape Coast

Skinner, B. F. (1963). Operant Behaviour. http://dx.doi.org/10.1037/h0045185. (18), 503-515

Teasley, M. L. (2004). Absenteeism and truancy: Risk, protection, and best practice implications for school social workers. Children and Schools, 26(2), 117-128.

Vidyakala1, K. \& Vaishnavi, M. (2015). Factors Influencing Student Absenteeism in School. https://www.ijsr.net/archive/v6i6/ART20174829.pdf

Vroom, V. (1964). Work and reinforcement. John Wiley \& Sons. 